\title{
Quo vadis energy sustainability?
}

\author{
Subhas K. Sikdar
}

Published online: 15 October 2009

(C) Springer-Verlag 2009

Analysis of the sustainability of any system is understood to examine the system performance from the perspectives of its impacts on three domains: environmental, economic, and societal. For energy systems, it is evident now that net greenhouse gas (GHG) emission concern has become the dominant driver for sustainability consideration. All western countries and most in the developing worlds have pledged to reduce GHG emissions in order to reverse potential ill effects of warming of the planet. Not all energy systems emit GHG, but the overall portion of the global energy use of those systems that are GHG-neutral currently is no more than $20 \%$. The important non-fossil energy systems with no net-positive GHG emission are nuclear, biomass and wastes, hydro, wind, solar, and geothermal. Oil $(34 \%)$, coal $(25 \%)$, and natural gas $(21 \%)$ not only constitute the main sources of the world's energy, but are also believed to continue to maintain similarly dominant position until about 2030, according to Energy Information Administration, as shown in Fig. 1 (EIA 2009a). To satisfy proclamations of draconian cuts in $\mathrm{CO}_{2}$ emissions by most western nations by this date, renewable and non-fossil energy systems would have to be rapidly developed and provided affordably. A recent EIA estimate showed that renewable energy production worldwide in 2025 could potentially reach greater than 200 quadrillion BTUs, which is double the entire U.S. energy use per year today. Even in that scenario, the total fossil energy use is not seen as substantially decreasing in absolute term.

As a result of the continued and increasing use of fossil fuels, carbon dioxide emissions will keep on increasing,

S. K. Sikdar $(\bowtie)$

National Risk Management Research Lab/USEPA, 26 West

Martin Luther King Drive, Cincinnati, OH 45268, USA

e-mail: sikdar.subhas@epa.gov though, as Fig. 2 shows, the emissions from the OECD nations will have stabilized by 2030, and most of the GHG emissions will come from the developing economies (EIA 2009b).

Carbon dioxide emission has become the main focus in debates on energy sustainability because most of these are derived from non-renewable fossil fuels used in power generation (coal and natural gas) and transportation (petroleum), and thus are deemed to be undesirable from global warming viewpoint. Even though over the longer term these are depletable resources, currently there is no shortage of these fuels. The supply and price of these fuels are largely controlled by the international cartel, and more sources are periodically discovered, adding to the recoverable reserves. The recent surge in world prices of fossil fuels resulted mainly from market disruptions and inevitable speculations in the futures market. One of the sustainability criteria any energy resource has to meet is whether we are keeping enough of that resource for the future generations. Fossil fuels do not have to meet this criterion because the resulting carbon dioxide emitted to the atmosphere is believed to do irreparable harm to all inhabitants of this planet because of global warming. This makes the case for drastically reducing the use of these fuels, while developing non-fossil routes to energy to power worldwide development. The U.S. National Research Council, in Grand Challenges for the Chemical Industries, foresees the transition to non-fossil fuels consummating by the turn of the 22nd century (NRC 2005).

Negotiations have been ongoing among the nations of the world since the signing of the Kyoto protocol on how to achieve the goal of stabilizing atmospheric $\mathrm{CO}_{2}$ at 500 $550 \mathrm{ppm}$-without success of any kind. Given the economic status of nations, self-interest differs from one another and that is reflected in their policy practices. The 


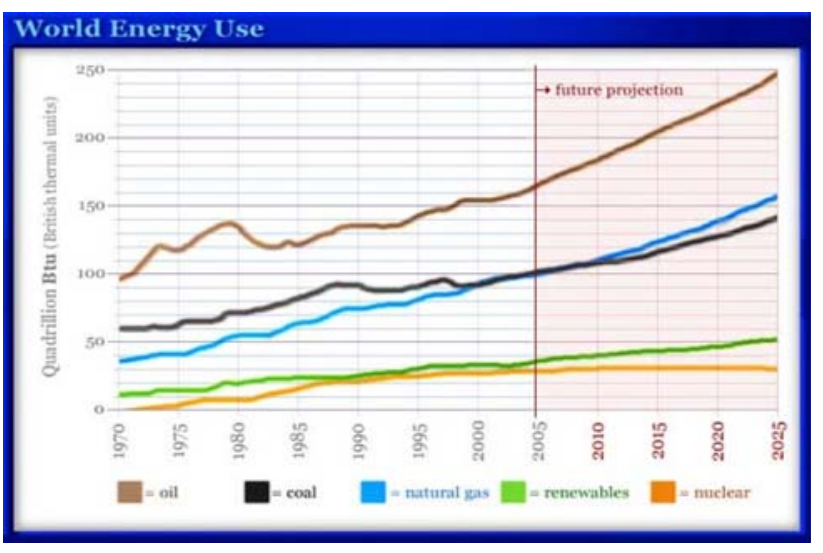

Fig. 1 Historic and projected world energy use by sources

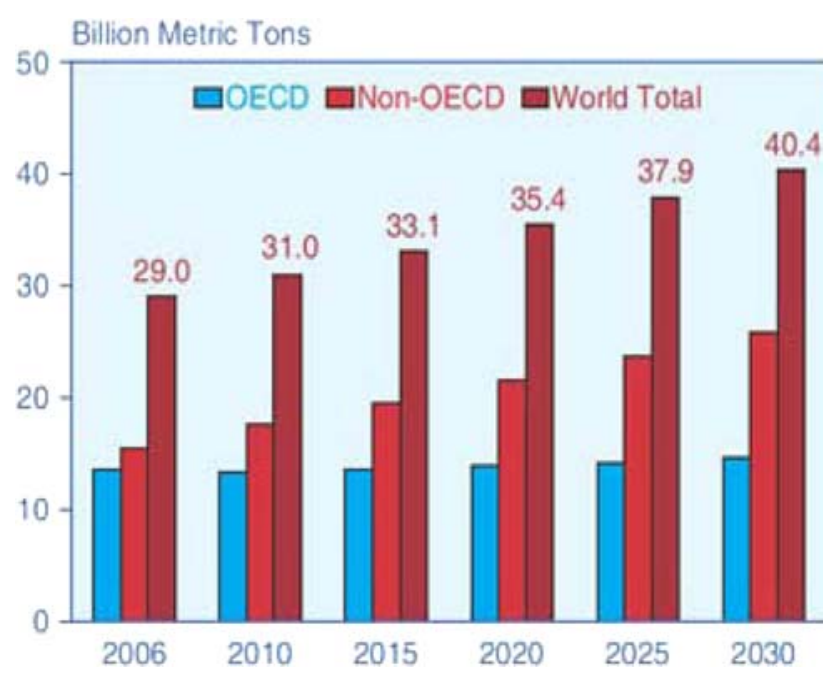

Fig. 2 Current and projected carbon dioxide emissions

G-20 summit in September this year in Pittsburgh has taken the topic again and we as observers wait to see what results from these discussions. However, serious research and development and pilot scale activities on many of the proposed alternatives are ongoing in many countries, and it is instructive to see the sustainability issues around these technology approaches for alternative energies.

Energy is the foremost driver of sustainability, as all development depends on affordable energy. Yet, it has to be emphasized that GHG emission is but one of many criteria that must be looked at critically before any energy solution or an ensemble of solutions is promoted as sustainable. There is always the fall back option of using fossil fuels, thus the dominant metric for comparison would have to be cost, currently viewed at about $\$ 2$ per million BTU. In a nutshell the current status of the alternative energy sources is the following:

- Fossil fuels: As long as fossil fuels are used, energy efficiency is a large contributor to sustainability. Significant gains have been made in this front. For the U.S. Fig. 3 shows that between 1980 and 2006, carbon dioxide emissions, in millions of metric tons per million (2000) dollars of GDP, have been cut by a third in the entire economy. The GDP in the same time interval has been doubled (from 5 to nearly 12 trillion dollars). While this is a remarkable achievement, U.S. still commands the largest ecological footprint of any nations. Compared to the U.K. or Germany, each of which has roughly similar GDP per person, another $50 \%$ reduction could be possible in U.S., as shown in Fig. 4 (Sikdar 2007).

Carbon sequestration is another avenue to fossil energy sustainability. This option, however, is limited to stationary point sources, such as power plants. Research and development in this area is being heavily funded by the U.S. Department of Energy. In this option, carbon dioxide needs to be first separated from other gases and compressed to supercritical condition and then pumped underground to depleted oil fields or saline aquifers. It is an expensive option, which will use upwards of $30 \%$ of the power generated. The price of electricity will have to go up,
Fig. 3 Evidence of energy efficiency of the U.S. economy
US CO2 emissions, metric tons/2000 million \$ GDP

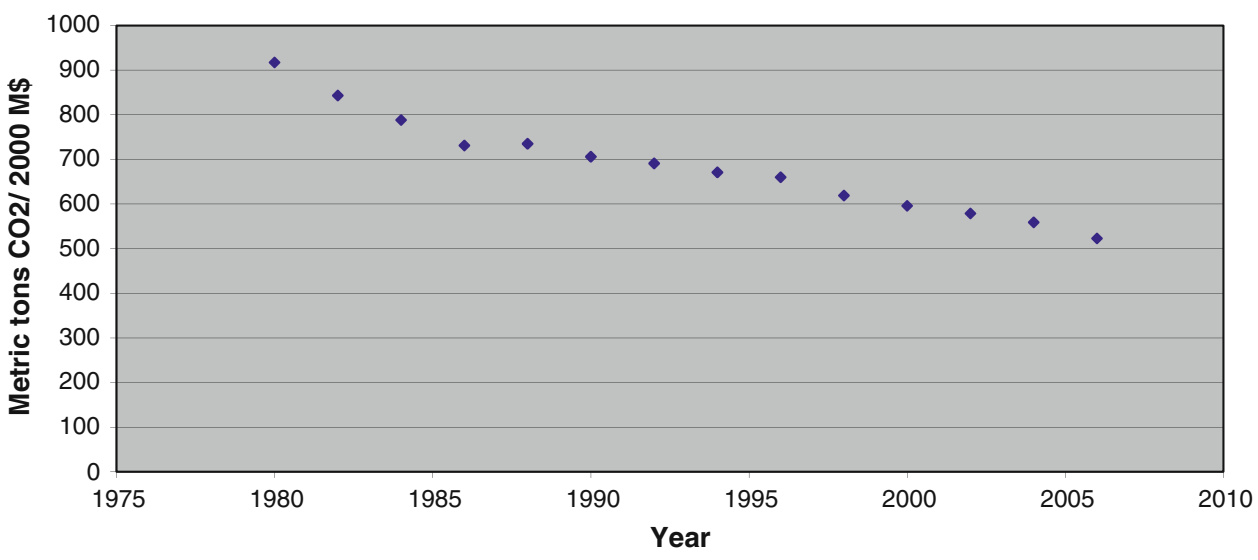




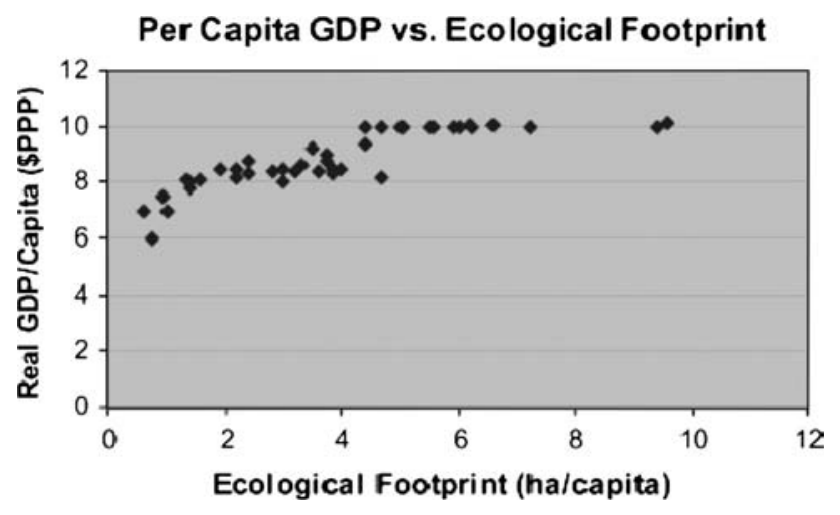

Fig. 4 Per-capita gross domestic product of nations versus the ecological footprint (reproduced from Bell and Morse 2003)

causing adverse societal impacts. Potential long-term impacts of sequestration on ground water chemistry and hydrology and carbon dioxide leakage are largely unknown but are being investigated. More than adequate sequestration capacity exists in the United States but it may not be an option for all regions of the world.

- Nuclear energy: Developing nuclear energy for any purpose comes under the purview of the International Atomic Energy Agency. Uranium-based power plants convert a tiny portion of the contained energy into power, creating high-level radiological wastes, which could be used for weaponization. Thus there is a highlevel barrier to entry to this energy source, and there is public opposition in many countries surrounding the safe disposal of the wastes. Even with somewhat more favorable attitude toward nuclear energy in some countries, as a result of concerns for energy security, not a significant gain is seen likely in the near future.

- Biomass: Biomass is seen as carbon neutral or carbon negative, yet none of the approaches: corn to ethanol, cellulosics to ethanol, and biomass to biocrude either through fermentation or thermochemical routes, is presently seen as competitive with petroleum. Thus there is subsidy being provided by various Governments as an interim measure to boost the economic efficiency of biomass conversion. This form of transportation fuel (currently limited to $10 \%$ mixed with gasoline in the U.S.) is vulnerable to petroleum price fluctuations. Recently several companies in the U.S. went bankrupt after the recent petroleum price collapse. However, serious and promising R\&D efforts are ongoing in the U.S., European Union (for biodiesel), and Brazil on improving process efficiency and cost reduction. The biomass to fuel approach has promise.

- Solar thermal: As a technology, this approach is viable, but restricted to certain regions of the world. Still, it is an intermittent source, and requires adequate storage technology. This is not being aggressively pursued anywhere.

- Photovoltaic electricity: Solar energy conversion in this form for power is the ultimate sustainability solution, but severe barriers remain to be overcome. Storage is one of them. Technology is the other. In current form, neither the silicon-based nor the thin film-based solar cells are economically competitive with either coal or natural gas for power generation. Serious R\&D efforts are ongoing in many countries to increase the cell efficiency, decrease the cost of solar cells, and develop adequate storage systems for electricity. Solar energy is subsidized in all countries at present (Spain recently cut the subsidy leading to a reduction of market penetration).

- Hydro power: There is significant capacity in many countries, and ecological impact concerns are an impediment to its further development. This form of power is not seen as developing significantly in the near future.

- Geothermal: For further development, reaching deep into the earth (several miles below the surface) is called for and serious technological difficulties exist. This form is also not seen as a significant contributor to the overall sustainability solution.

Each of the alternatives exhibits significant barriers to sustainability. For instance, biomass conversion creates concerns of land use, biodiversity loss, and water pollution. In addition, neither utility scale power plants nor very large scale transportation fuel conversion facility can be seen as solution because of procurement and transportation issues. Clean coal technology, in which carbon dioxide is separated, compressed, and sequestered in deep aquifers, can be a fossil-fuel-based sustainability solution, but the consequences of sequestration are largely unknown, and are being investigated.

Energy sustainability is a good goal but the challenges are enormous. There is no royal road to energy sustainability. Attaining this goal is the grandest challenge before the scientists and engineers of the 21st century.

\section{References}

Bell S, Morse S (2003) Measuring sustainability: learning by doing. Earthscan Publications Limited, London, UK

EIA (2009a) International Energy Outlook

EIA (2009b) World Energy Projections Plus

National Research Council (2005) Sustainability in the chemical industry: grand challenges and research needs. A workshop report. National Research Council, Washington, DC. Available via the Internet at http://www.nap.edu/catalog//11437.html

Sikdar SK (2007) Sustainability and chemistry-based technologies. I\&EC Research 46:4727-4733 